\title{
Qualitative research in adolescent psychotherapy: Attachment and Reflective Functioning as psychotherapy's outcomes of an adolescent with anorexia nervosa
}

\author{
Ester D'Onofrio ${ }^{1}$, Cecilia Serena Pace ${ }^{2 \bowtie}, \&$ Donatella Cavanna ${ }^{2}$
}

\begin{abstract}
The aim of this study was to examine both the change in attachment state of mind and mentalization competencies as outcomes of a two-year weekly psychodynamic psychotherapy of a female adolescent with anorexia nervosa. The Attachment Interview for Childhood and Adolescence (AICA) was administered at pre and posttreatment, and coded both with the attachment coding system and the Reflective Functioning $(\mathrm{RF})$ scale. At the pre-treatment, the anorexic adolescent was assessed as insecure-dismissing with very low level of RF, while in the post-treatment a secure attachment model and higher RF were highlighted. The AICA can be considered a useful method to assess the outcomes in adolescent psychotherapy, like the AAI is useful in adult psychotherapy.
\end{abstract}

Keywords: adolescent psychotherapy; anorexia nervosa; attachment and reflective functioning

This qualitative study examined the changes in the attachment pattern and reflective functioning of a female adolescent patient with anorexia nervosa (AN) occurring after two years of psychoanalytic psychotherapy. AN is an eating disorder with a complex pathogenesis prevailing in female gender (90$97 \%$ ) with initial onset between 10 and 20 years of age, bringing severe psychological and physiological consequences (Cai et al., 2008; Laghi, Baiocco, Ghezzi, Petrocchi, \& Pace, 2012;; Preti et al., 2007; Treasure, Schmidt, \& Van Furth, 2006).

Adolescence (early adolescence, in particular) can be defined as a process of adjustment and settlement of psychological and social functioning due to the transformations of the body induced at puberty (Brooks-Gunn \& Paikoff, 1997; Pace, San Martini, \& Zavattini, 2011). Changes in puberty involve both the physical shape of the body and the endocrine system, and they are accompanied by cognitive changes (Cromer, Schembri, Harel, \& Maruff,

\footnotetext{
${ }^{1}$ Department of Clinical and Dynamic Psychology, La Sapienza, University of Rome.

${ }^{2}$ Department of Educational Science; University of Genova.

Correspondig Author: Prof. Cecilia Serena Pace, PhD, Università di Genova, Italy; email to: cecilia.pace@unige.it
}

2015; Sprondel, Kipp, \& Mecklinger, 2011). As a consequence of body transformations and sexual impulses, the body becomes the privileged centre of conflicts during adolescence. At this stage, the body can be considered an "organizer" and assumes the central role of mediator with respect to the external world, becoming the place for contrasting desires (Zavattini, 2002). At the same time adolescents may feel both the lack for their childlike images of the bodily self, tied to parental figures, and they may feel overwhelmed by the pressure of change in the search for their own individuality. Therefore, the body could display adolescents' emotional and relational problems and, through it, teenagers may experience very deep discomfort, as occurs in females with AN in which the body becomes a privileged outlet to express their repressed mental states (Fonagy \& Target, 2001; Jeammet, 2006).

In the last 20 years, attachment theory has received increasing attention from clinicians and researchers in the field of eating disorders (ED), producing enough clinical studies so that three reviews have recently been published (Cavanna, Delogu, \& Zavattini, 2012; O'Shaughnessy \& Dallos, 2009; Zachrisson \& Skårderud, 2010). Many studies have specifically highlighted the role played by attach- 
ment states of mind, intended as narrative representations of attachment relationships assessed by the Adult Attachment Interview (AAI; George, Kaplan, \& Main, 1985), on the development and maintenance of ED (Bakermans-Kranenburg \& van IJzendoorn, 2009; Cassibba, Sette, Bakermans-Kranenburg, \& van IJzendoorn, 2013). Up to now, studies specifically with AN patients showed that their attachment states of mind were characterized by an overall over-representation of insecurity, ranging from 70 to $90 \%$ (Barone \& Guiducci, 2009; Cole-Detke \& Kobak, 1996; Del Vecchio, Di Riso, Salcuni, Lis, \& George, 2014; Dias, Soares, Klein, Cunha, \& Roisman, 2011; Ringer \& Crittenden, 2007; Ward, Ramsay, Turnbull, Steele, Steele \& Treasure, 2001; Zachrisson \& Kulbotten, 2006). Most studies have reported high prevalence of insecure-dismissing states of mind, characterized by a state of mind tending to minimize, derogate, and normalize attachment experiences and relationships. However, other studies have found both dismissing and insecure-entangled patterns, characterized by a state of mind tending to emphasize attachment experiences and relationships in an angry, passive, or preoccupied manner, which were associated with the purging subtype of AN. Lastly an over-representation of unresolved loss or abuse, or both was identified by local and trauma-specific disorganized speech when discussing these distressing events, such as collapse of reasoning and discourse monitoring abilities. Moreover, studies on attachment states of mind of parents, mostly mothers, of young patients with ED showed high incidence of insecurity and unresolved loss (Delogu, Tortolani, \& Zavattini, 2008; Pace, Cavanna, Guiducci, \& Bizzi, 2015; Ward et al., 2001).

Some researchers have showed that insecure and unresolved attachment states of mind are connected to low levels of mentalization in terms of low reflective functioning, intended to represent one's own and significant others' mental states, including the caregivers (Dazzi \& Zavattini, 2011; Jacobvitz, Hazan, \& Riggs, 1997; Van IJzendoorn, Schuengel, \& Bakermans-Kranenburg, 1999).

Some authors suggest that through ED symptomatology the body becomes a way to express negative feelings and difficulties, which is a result of failed mentalization ability that seems to force the adolescent to manage thoughts, feelings, and desires at a physical level through bodily processes and states (Fonagy \& Target, 1988; Skårderud, 2007). In this line, some studies have pointed out that AN is often accompanied with a sort of concretization of the symptoms together with meta-cognitive difficulties, problems in tasks based on the theory of mind, and maladaptive beliefs not only concerning the weight, shape, and size of the body but also a deficit of reflective functioning (Russell, Schmidt, Doherty, Young, \& Tchanturia, 2009). Several authors highlighted significantly lower scores on the
Reflective Function (RF) scale in a sample of patients with ED compared with a nonclinical control group (Fonagy et al., 1996; Rothschild-Yakar, LevyShiff, Fridman-Balaban, Gur, \& Stein, 2010). These findings were confirmed by another study showing low scores on the RF scale in a sample of anorexic girls and their mothers (Ward et al., 2001).

Beyond clinical studies that examined the associations between psychiatric diagnosis, insecuredisorganized attachment states of mind and poor mentalization ability, in the recent years an increasing body of literature has highlighted the clinical applications of the AAI (Steele \& Steele, 2008a). Within this research area, as some attachment clinicians and researchers have suggested (Steele \& Steele, 2008b), there is the evaluation of therapeutic outcomes both in randomized controlled treatment trials and qualitative case studies. The last ones include the repeated administration of the AAI at the beginning of treatment, providing a detailed picture of the patient's internal world and, at the end of years of psychotherapy, captured the shift from deeply insecure states of mind to less insecure and more organized ones together with an improvement of the patients' reflective functioning.

Furthermore, from a clinical perspective, a growing number of studies on attachment focused on "bridging the gap" between research and clinical applications, and some clinicians and researchers highlighted how attachment themes can be useful within psychoanalytic psychotherapy and parentchild psychotherapy (Obegi \& Berant, 2009; Steele \& Baradon, 2004; Steele \& Steele, 2008b). For example, Arietta Slade pointed out how, beyond the mere AAI classification, the patient's attachment representation and reflective function can be considered as affect and relation regulation strategies, and they are relevant constructs for therapeutic work as well as psychoanalytic concepts are (Slade, 2010). In addition, David Wallin highlighted how the patient's attachment organization can help the therapist understand the patient's transference and counter-transference dynamic, especially regarding separation and rupture in the psychotherapeutic process (Wallin, 2009).

However, the case studies literature has been mostly focused on qualitative research of adult patients in psychotherapy, while up to now less is known about the use of the AAI or its adaptation for younger patients, the Attachment Interview for Childhood and Adolescence (AICA; Ammaniti et al., 1990) in psychotherapy research with adolescent patients (Ammaniti, Dazzi, \& Muscetta, 2008).

\section{Method}

A single case of a female adolescent with AN was used. She presented clinically significant changes in her attachment states of mind, reflective functioning, and emotional regulation strategy, following 
psychotherapeutic treatment.

\section{Patient's Presentation}

The patient's name was "Sarah." She received the diagnosis of AN according to the DSM-IV-TR (American Psychiatric Association, 2000) via a clinical interview and her responses to the Eating Disorder Inventory-3 (EDI-3; Garner, 2008) upon which scores placed her in a clinical range for seven of the 12 subscales (e.g. thinness impulse).

Sarah lost her father when she was one year old and she was living with her mother and two older brothers. She was 16 years old when she started psychotherapy treatment, and she attended the second year of high school with excellent academic achievement.

The patient showed the following symptoms:

1. Refusal to maintain body weight at or above a minimally normal weight for age and height: At the time of intake, Sarah weighed $36 \mathrm{~kg}$ and she was $160 \mathrm{~cm}$ tall.

2. Intense fear of gaining weight or becoming fat, even though underweight: Although Sarah was very thin with a body mass index (BMI) of 14, she continued to refuse food for fear of gaining weight.

3. Disturbance in the way in which one's body weight or shape is experienced, undue influence of body weight or shape on self-evaluation, or denial of the seriousness of the current low body: Sarah was used to wearing big clothing sizes, and, during the initial phase of psychotherapy, she was completely focused on her seeing herself as fat and all the exercises she had to perform to lose weight.

4. In postmenarchal females, amenorrhea (i.e., the absence of at least three consecutive menstrual cycles): When Sarah started psychotherapeutic treatment, her menstrual cycle had been absent for four months.

According to the DSM-IV-TR, Sarah was classified as restrictive subtype AN because she was used to fasting for long periods, even though she took laxatives or diuretics whenever she rarely ate small food amounts. Sara was assessed both by the psychiatrist and the psychotherapist via the clinical interview and the examination of her medical history. Initially Sarah's anorexic symptoms were egosyntonic: she did not perceive the danger of her excessive thinness, indeed she claimed to be fat. For this reason, Sarah's motivation for the treatment was low: she refused the therapist's help and she often missed sessions. Moreover, Sarah's excessive control over her body significantly lowered her reflective functioning.

\section{Treatment}

The patient was involved in psychoanalytic psychotherapy twice weekly for two years. The treatment began in September 2010 and ended in September 2012.

Due to Sarah's low weight, she was initially followed by a multi-disciplinary team: a group of dieticians weekly checked her physical conditions through weight check and blood analysis, and a psychiatrist prescribed her drugs. The multidisciplinary team (psychiatrist, dieticians and psychotherapist had a monthly meeting to discuss the case. They decided to wait three months to see whether Sarah would be able to eat and gain weight, otherwise the young patient would be admitted as inpatient in a hospital. During the first months, Sarah started to eat small quantity of food and she slowly began to gain weight. Meanwhile, Sarah's mother has been assisted by a family therapist for one year, and then she decided to interrupt the therapy, although she kept contact with her daughter's psychoanalytic therapist.

\section{Measurements and Coding Systems}

The Attachment Interview for Childhood and Adolescence (AICA; Ammanniti et al., 1990). The patient was administered the AICA, which is an adaptation of the AAI for teenagers. The contents are similar to those of the AAI, but some questions have been linguistically simplified and others added to capture specific characteristic of attachment in adolescence (e.g., peers relationships). The AICA is an hour-long, semi-structured interview and is focused on the interviewee's relationships with attachment figures during childhood and early attachment experiences, such as those occurring due to illness, upset, separation, loss, etc. It asks them to provide specific episodes to support their general memories. They were also asked to reflect both on how attachment experiences had influenced their personality and the reasons for parents' behavior toward them during childhood. The AICAs were audio-recorded and transcribed verbatim.

The Attachment Scoring and Classification System (Main, Goldwyn, \& Hesse, 2002). The AICA (and the AAI) original coding system employs 17 ordinal scales of 1 (no/not at all/lacking in) to 9 (extreme/highly/very strong/very frequent) points each and is organized into two groups: (1) subject's inferred childhood experience (loving, rejecting, neglecting, role reversal and pressure to achieve, each one related both to the mother and father) and (2) current attachment mental states. Both are related to parental (idealization, anger, derogation) and global (coherence of transcript, coherence of mind, lack of memory, metacognition, passivity, fear of loss, unresolved loss, unresolved abuse) aspects.

Therefore, five attachment classifications are obtained, three organized: free-autonomous $(\mathrm{F})$, dis- 
missing (Ds), entangled (E) and two not organized: unresolved with respect to loss or abuse (U) and cannot classify (CC) that could be added to the three main ones. These latter two were often considered together in a not-organized (U/CC) group (Bakermans-Kranenburg \& van IJzendoorn, 2009).

The central feature of the AAI and AICA coding systems is that it is not limited to assess the content as positive or negative early childhood attachment experience, and it also aims to evaluate the states of mind with respect to attachment throughout the discourse with the interviewee, mostly captured by the Coherence of Transcript scale. In other words, as mentioned above, highly coherent narratives could report a positive or very loving childhood, recalling biographical episodes that are fresh and authentic and that support the patient's claims, or they could report negative or even traumatic childhood experience, but in a contained and consistent manner, relating events truthfully and being neither excessively blaming nor dismissing of the importance of adverse events.

Psychometric studies in many countries have shown that the attachment classifications provided by AAI are steady over periods of up to 15 months, and do not depend on the interviewer. The AAI categories were not correlated to the interviewees' cognitive level, social desirability, memory and general discourse style (Bakermans-Kranenburg \& van IJzendoorn 1993; Crowell et al., 1996). As far as AICA is concerned, the attachment classification distributions did not differ from the AAI distributions, the stability of attachment security was considerable, especially for dismissing and secure categories, and no significant gender differences in attachment emerged in early adolescence (Ammaniti, van IJzendoorn, Speranza, \& Tambelli, 2000).

The Reflective Functioning scale (Fonagy, Steele, Steele, \& Target, 1998). The Reflective Functioning (RF) scale (Fonagy et al., 1998) evaluates the quality of mentalization in the context of attachment relationships and refers to the following four indexes: (1) awareness of the mental states' nature (i.e., their opacity), (2) explicit attempts to bring out the mental states underlying behavior, (3) acknowledgment of the developmental aspects of mental states, (4) awareness of mental states with respect to the interviewer.

The RF scale was originally applied to AAI, but it can be utilized also with AICA with the same rules, due to the same structure of the two interviews (Fonagy et al., 1998; Ammaniti et al., 1990). Some studies with AICA showed a good applicability of the RF scale in early and late adolescence, both to clinical and non clinical samples (Ammaniti, Zavattini, Tambelli, Vismara, \& Volpi; 1999; Guarino \& Vismara, 2012).

To assess the RF, the questions of the AAICA (like the AAI) are divided into two groups: seven demand questions essential for the RF coding system, which force the interviewee to show his or her own RF ability (i.e., "How do you think that the overall experience with your parents during childhood has affected the development of your personality as adult?"; "Why do you think your parents behaved as they did in your childhood?"), and the permit questions, consisting of the remaining questions of the AAI that allow the respondent an opportunity to use mentalization skills.

The RF scale is an 11-point scale ranging from -1 (negative RF in which interviews are overly concrete, totally barren of mentalization, or grossly distort the mental states of others) to 9 (exceptional $\mathrm{RF}$ in which interviews show unusually complex, elaborate, or original reasoning about mental states).

Scorings on RF were not correlated with IQ and personality traits. Studies showed good inter-rater reliability, high correlations between parental RF scores and children's attachment patterns, and good validity of RF to predict presence/absence of psychopathology in adults (Fonagy, et al 1998).

\section{Procedures}

Pre-treatment: The AICA was administered to Sarah at the beginning of psychoanalytic psychotherapy (AICA-T1). The psychotherapist explained to Sarah that she was used to administer an interview at the beginning of the treatment in order to better understand her patients' histories and feelings. The pre-treatment AICA was very hard for Sarah who was not used to speak about herself. However, the interview allowed Sarah to think of her past history maybe for the first time. Moreover, to know Sarah's attachment models allowed the therapist to understand her affect regulation strategies and to soonadapt the therapy to her in order to foster therapeutic alliance.

Treatment. During treatment, the initial obsession for food and weight slowly disappeared, leaving space to Sarah's deep feelings, such as pain and anger to be neglected in her childhood. Meanwhile(,) her relationship with the therapist gradually changed and Sarah learnt to trust her.

Post-treatment: The AICA was administered again to the patient by her psychotherapist at the end of treatment, after two years of twice weekly psychoanalytic psychotherapy (AICA-T2).

\section{Results}

\section{The Pretreatment of Sarah's AICA}

Attachment states of mind. As shown in Table 1, Sarah's pretreatment AICA was classified as dismissing of attachment (Ds1), an insecure state of 
mind indicating a current attempt to limit the influence of attachment relationships and experiences in thought and feeling, through dismissing possible imperfections of the parent in the face of contradictory or unsupportive evidence.

Table 1. Ratings of Sarah's AICA

\begin{tabular}{|c|c|c|c|c|}
\hline & \multicolumn{2}{|c|}{ AICA - TIME 1} & \multicolumn{2}{|c|}{ AICA - TIME 2} \\
\hline & Mother & Father & Mother & Father \\
\hline \multicolumn{5}{|c|}{ Experience scales } \\
\hline Loving & 3 & NC & 2 & NC \\
\hline Rejecting & 1 & NC & 1 & NC \\
\hline $\begin{array}{l}\text { Involving role } \\
\text { reversal }\end{array}$ & 3 & NC & 1,5 & $\mathrm{NC}$ \\
\hline Pressure to achieve & 1 & NC & 1 & $\mathrm{NC}$ \\
\hline Neglect & 1 & NC & 1 & NC \\
\hline \multicolumn{5}{|c|}{ States of mind scale } \\
\hline Idealization & 6.0 & NC & 2.0 & $\mathrm{NC}$ \\
\hline Anger & 1 & NC & 1 & $\mathrm{NC}$ \\
\hline Derogation & 1 & NC & 1 & NC \\
\hline Overall derogation & \multicolumn{2}{|c|}{1} & \multicolumn{2}{|c|}{1} \\
\hline $\begin{array}{l}\text { Insistence of lack } \\
\text { of recal }\end{array}$ & \multicolumn{2}{|c|}{6,5} & \multicolumn{2}{|c|}{2.0} \\
\hline $\begin{array}{l}\text { Metacognitive } \\
\text { process }\end{array}$ & \multicolumn{2}{|c|}{1} & \multicolumn{2}{|c|}{1} \\
\hline Passivity & \multicolumn{2}{|c|}{1} & \multicolumn{2}{|c|}{1} \\
\hline Fear of loss & \multicolumn{2}{|c|}{1} & \multicolumn{2}{|c|}{1} \\
\hline Unresolved for loss & \multicolumn{2}{|c|}{1} & \multicolumn{2}{|c|}{1} \\
\hline $\begin{array}{l}\text { Uresolved for } \\
\text { trauma }\end{array}$ & \multicolumn{2}{|c|}{1} & \multicolumn{2}{|c|}{1} \\
\hline $\begin{array}{l}\text { Coherence of } \\
\text { transcript }\end{array}$ & \multicolumn{2}{|c|}{3} & \multicolumn{2}{|c|}{6} \\
\hline Coherence of mind & \multicolumn{2}{|c|}{3} & \multicolumn{2}{|c|}{6} \\
\hline Classification & \multicolumn{2}{|c|}{ Ds1 } & \multicolumn{2}{|c|}{$\mathrm{F} 2$} \\
\hline
\end{tabular}

Note. NC: Not Classificable; Ds: Dismissing; F: Free

In terms of states of mind scales, the AICA received high scores both on the Idealization of Mother scale (6 points), representative of a discrepancy between the semantic picture of the parent as normally supportive and on episodic memory from childhood, which fails to support the positive picture of parent, and the Insistence on Lack of Recall scale ( 6.5 points), indicative of a tendency to block discourse thorough an absence of memory for childhood. In line with these scores, the AICA-T1 obtained low ratings both on the Coherence of Transcript and Mind scales (3 points), connected with the violations both of the quality ("Be truthful and have evidence for what you say") and quantity maxims ("Be succinct, yet complete").

Sarah, in order to describe the relationship with her mother during childhood, provided a set of very positive adjectives, such as "exceptionally good," "very sweet," and "very careful," which she was never able to support with specific episodes from her childhood, as in the following example:

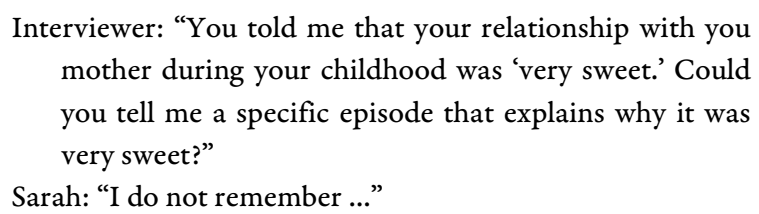

Moreover, the patient tended to normalize the negative effects of her past experience on herself, saying as follows "When I was a child, my mother would scold me so strongly, but this is something that many parents do."

With respect to the scales for inferred experiences with parents, the Sarah's AICA-T1 received low scores on the Loving scale (3 points) due to her inability to provide specific episodes to support the positive adjectives selected together with mild ratings on the Role Reversal scale (3 points) as emerged in the following sentence: "When my mother felt a bit 'down' at home, I took care about all the stuff, and this made her feel better."

As shown in table 1, Sarah was not able to answer AICA questions about the relationship with her father because he died when she was only one year old. At the beginning of THE treatment, Sarah was not able to say anything about her father, after a while she became able to speak about him showing indifference, and later she expressed pain for her father's loss and for not having known him.

Reflective Functioning scale. In the RF scale (Fonagy et al., 1998) Sarah obtained a score of 1 on the AICA-T1 that, according to the RF manual's criteria, indicates her RF was absent, but not rejected. The patient did not show hostility during the AICA; however, she presented a kind of passive avoidance of the topics requiring the use of mentalization skills. Indeed, Sarah's explanations in terms of mental states are concrete and self-reported (Cavanna, 2011). In the next brief excerpt, an example of a 1 point score on the RF Scale was reported.

Interviewer: "Why do you think your mother behaved as she did with you during your childhood?"

Sarah: "What do you mean?"

Interviewer: "As you told me she behaved with you."

Sarah: "Ehm (2 sec.) Because (4 sec.) I do not know."

\section{The Posttreatment of Sarah's AICA}

Attachment states of mind. After two years of psychoanalytic psychotherapy, Sarah's AICA-T2 classified her as secure with respect to attachment, 
somewhat restricting (F2). The F2 subcategory refers to individuals who appear to be initially defensive regarding attachment or are held back by some kind of dismissal of attachment, ultimately belied by affection, forgiveness, or other evidence of an underlying value of attachment.

This change of the AICA's classifications shows that Sarah, after two years of treatment, is able to recognize negative behavior from her mother during childhood and to freely discuss them. Therefore, she lost her dismissing strategy to become securely attached.

In line with the classification change, her scores both on Maternal Idealization and Insistence on Lack of Recall scales had dramatically decreased (both 2 points) and scores on both Coherence of Transcript and Mind scales had risen (6 points).

At Time 2, Sarah reported a less positive and balanced series of adjectives to describe her relationship with her mother during childhood (i.e., "not very present," "a bit complicated," etc.), and she appeared more able to provide some examples, although the ability to report specific episodes remained limited. The following excerpt gives the sense of Sarah's new stance.

Interviewer: "You told me that your relationship with you mother during your childhood was "not very present." Could you tell me a specific episode about this?"

Sarah: "Yes, unfortunately, when I was child my mother was not very present, and when she was there, she was not able to take care of me emotionally. She brought me to school and she was good in the things I had to do, so she helped me to do my homework, but if I had some difficulties I never felt understanding from her."

Sarah was able to freely discuss her negative experiences with her mother in a more critical and elaborate way, losing her previous idealizing (and defensive) position toward her.

With respect to the Inferred Experiences scales, the scores both on Loving and Role Reversal scales remained low (both 2 points), but the patient was aware of the effects of those experiences upon her current states of mind, as shown in the passage that follows: "I think that all the experiences I lived during my childhood in the relationship with my mother have affected how I am today. Indeed I had a lot of difficulty to ask for help and get in touch with other people, because I took care of my mother when I was child, so I knew how to give help, but not to ask for help."

Reflective Functioning scale. At Time 2, the transcript scored 5 on the RF scale as occurs when an individual shows RF is "defined and ordinary." To obtain this score, the AICA should explicitly show reflective abilities, although they do not need to be sophisticated or introspective.
As the following brief excerpt shows from the AICA-T2, Sarah seemed able to provide explanations in terms of mental states, highlighting a medium level of mentalization development.

Interviewer: "Why do you think your mother behaved with you during childhood as you told me?".

Sarah: "I think my mom is made in that way... Then I think also that, you know, the death of my father definitely had a strong impact on her state of mind; she was very much destabilized from Dad's loss, so she was in pain and I tried to protect her and I took care of her."

\section{Discussion}

At the end of two years of psychoanalytic psychotherapy with respect to AN symptoms, Sarah ate much more food, reached a BMI of 19.1, and, after one year and half of amenorrhea, regained her menstrual cycle.

The literature on the clinical uses of the AAI has shown that pretreatment assessment can provide useful information about the patient's current mental state with respect to attachment, which can be seen as the result of patients' personal elaboration of past relationships with attachment figures, implying the type of strategies used in current significant relationships (Slade, 2010). When the clinician knows "the way to stay in the world of the patient" (Wallin, 2009) it will greatly help her understand the patient's basilar emotional and relational strategies. This awareness also benefits the psychotherapeutic relationship by inducing the clinician to adapt to her usual adaptive strategy (Steele \& Steele, 2008b).

The AICA-T1 administered to our anorexic adolescent patient revealed a dismissing state of mind, characteristic of patients with strong difficulty to be collaborative, truthful, and complete and tending to show a defensive pattern that idealizes or derogates their parents. Thereby, the AICA-T1 permitted the psychotherapist to understand that Sarah developed both a highly idealizing stance and reduced mentalization in order to defend herself from a maternal figure she experienced as absent and poorly attuned to her emotional needs as a child.

The use of the AICA at the pretreatment stage allowed the clinician to explore Sarah's dynamics early, which otherwise probably would emerge only over time, and enabled her to act in a timely manner on Sarah's unelaborated areas. This is a relevant goal for adolescent patients with AN whose health and development are at great risk (Steele \& Steele, 2008a). For Sarah, in line with her difficulties to agree to seek help, it was very difficult to trust and rely on therapy, because she did not believe that there might be someone able to take care of her. This rigid and controlling tendency hid a strong fear of linking to someone else who, at any moment, 
could abandon her again, as both her parents had done in the past; her father had died and her mother had been absent of emotional support. Therefore, the dismissing model that had emerged through the AICA-T1 was also expressed in the psychotherapy sessions. Sarah, on one hand, showed fear that her expectations could be again "confirmed," namely the therapist would abandon her as her mother had, on the other hand, she searched for a new attachment figure who would be present and attuned to her emotional needs, although this would imply a commitment to involve more herself in the therapeutic relationship and face the change. For the therapist, being able to reflect on Sarah's emotional strategies underlying her dismissing attachment classification via the AICA, allowed her to get an idea about the patient's suffering, the reasons for her lack of cooperativeness and self-closure, which in turn hid a strong fear that others would leave her.

Further, the AICA-T1 revealed Sarah initially showed great difficulties in mentalizing processes and any attempt to access to her emotional experiences appeared locked, highlighting an inability to contact emotions and to reason in term of mental states. Sarah's low mentalizing competence confirmS studies on RF in adolescent clinical population which showed impaired mentalizing in adolescents with Borderline Personality Disorder features and criminal offenders, revealing also that RF moderates the relationship between parental neglect and attachment classification in adolescence (Borelli, Jessica, Compare, Snavely, \& Decio, 2015; Ha, Sharp, Ensink, Fonagy, \& Cirino, 2013; Möller, Falkenström, Holmqvist Larsson, \& Holmqvist, 2015). From a clinical perspective, despite the mentalizing development occurring in adolescence, a teenager who suffers of affective and relational deprivations in childhood from attachment figures could experience again rejection, and so he/she could deny parental mental states inhibiting his/her ability to reflect.

The psychotherapist initially had the impression that the patient had built, in the course of her existence. a defense completely based on self-sufficiency and concrete goals, without any space for her internal world, such as thought, motivations, feelings, and desires. For Sarah, self-sufficiency and concrete goals seemed to be the only tools for coping with her intense desire for dependence.

The use of the AICA at the end of treatment, as underlined in the introduction, permitted us to observe the changes in Sarah's representational world. The AICA-T2 was assigned to the F2 subcategory, which referred to secure individuals who value attachment relationships in an independent and objective manner, although they maintain some dismissing characteristics, such as mild idealization of one parent.

The psychotherapist's responses during treat- ment tended to find a balance between "nonintrusive" and "not-dismissing" figure, which allowed to Sarah to gradually rely and trust the therapeutic bond. Across the sessions, Sarah slowly reported frequent quarrels with her mother who, according to the AICA-T1, was described as "perfect." According to the AICA-T2, she experienced the relationship in a more realistic and less idealized way. During the treatment, Sarah probably felt supported because there was a mind - the therapist's mind - that could take care of her. This enabled the patient to shift towards secure attachment states of mind, after acquiring a good understanding of her past history.

Thus, during psychoanalytic psychotherapy, Sarah could experience a new attachment figure - the therapist - who had "her mind in mind," and this helped her identify her emotions related to anorexic symptoms and reduce her anxiety and confusion. The first therapeutic sessions were completely focused on food and Sarah's body, but with time the patient began to turn her focus on an emotional level. The patient, in the course of psychoanalytic therapy, gradually increased her mentalizing ability and slowly learned to express her difficulties and needs, becoming aware of emotions she never felt before, such as anger and sorrow. These movements of the patient suggest that she has stabilized her self-regulation and has become more comfortable with her own problems and emotional experiences. The therapeutic relationship has enabled her to shift toward a more mature emotional regulation, allowing Sarah to get in touch with her emotions, without addressing anorexic symptoms.

Despite the promising results, this single case study showed several limitations. First, the findings provide just an example and they cannot be generalized to the clinical use of AICA to assess treatment in adolescent with ED. Second, as there are no other comparable data, it is not possible to say if the outcomes are related to the specific ED diagnosis, or if they are aspecific. Third, the AICA, as the AAI, is an expensive and time-consuming interview that needs a very long and intensive training to learn how to use it. However, the results can be very useful for the clinician, because AICA provides a special method to capture both the inner world of the adolescent patient and the representational changes that might; occur in the course of psychotherapy, beyond the remission of the symptoms.

\section{References}

American Psychiatric Association (2000). Diagnostic and Statistical Manual of Mental Disorders, DSM-IV-TR. [Italian translation Manuale Diagnostico Statistico dei Disturbi Mentali, DSM-IV-TR. Masson, Milano, 2000].

Ammaniti, M., Candelori, C., Dazzi, N., De Coro, A., Ortu, F., Muscetta, S., Pola, M., Speranza, A.M., Tambelli, R., \& Zampino, F. (1990). IAL. Intervista sull'attaccamento nel- 
la latenza. [AICA Attachment Interview in Childhood and Adolescence]. Manoscritto non pubblicato, Università degli Studi di Roma.

Ammaniti, M., Zavattini, G.C., Tambelli, R., Vismara, L., \& Volpi, B. (1999). Attaccamento e Funzione Riflessiva in adolescenza [Attachment and Reflective Function in Adolescence], Psicologia clinica dello sviluppo, 1, 155-176. doi: $10.1449 / 551$

Ammaniti, M., Dazzi, N., \& Muscetta, S. (2008). The AAI in a clinical context: Some experiences and illustrations. In $\mathrm{H}$. Steele, M. Steele (Eds.), Clinical applications of the Adult Attachment Interview (pp.236-269). New York: Guilford Press.

Ammanniti, M., Van IJzendoorn, M. H., Speranza, A. M., \& Tambelli, R. (2000). Internal Working Models of attachment during late childood and early adolescence: An exploration of stability and change. Attachment and Human Development, 2(3), 328-346. doi: 10.1080/14616730010001587

Bakermans-Kranenburg, M. J., \& van IJzendoorn, M. H. (1993). A psychometric study of the adult attachment interview: Reliability and discriminant validity. Developmental Psychology, 29(5), 870-879.

doi: 10.1037/0012-1649.30.5.771

Bakermans-Kranenburg, M.J., \& van IJzendoorn, M.H. (2009). The first 10000 Adult Attachment Interviews: distribution of adult attachment representations in clinical and non-clinical groups. Attachment \& Human Development, 11(3), 223-263. doi: $10.1080 / 14616730902814762$

Barone, L., \& Guiducci, V. (2009). Mental representation of attachment in eating disorder: A pilot study using the Adult Attachment Interview. Attachment and Human Development, 11(4), 405-417. doi:10.1080/1461673031000078634

Borelli, J.L., Compare, A., Snavely, J.E., \& Decio, V. (2015). Reflective functioning moderates the association between perceptions of parental neglect and attachment in adolescence. Psychoanalytic Psychology, 32(1), 23-35. doi: http://dx.doi.org/10.1037/a003785

Brooks-Gunn, J., \& Paikoff, R., (1997). Sexuality and developmental transitions during adolescence. In Schulenbenrg, J., Maggs, J.L., Hurrelman, K., Health risks and developmental transitions during adolescence. New York: Cambridge University Press.

Cai, W., Miriam E., Arner, B., Candice N., Walsh, B, Foltin, T., Richard W., Hoebel, B.G., Barbarich, \& M., Nicole C. (2008). Activity-based anorexia during adolescence does not promote binge eating during adulthood in female rats, International Journal of Eating Disorders, 41(8), 681685. doi: $10.1002 /$ eat.20568

Cassibba, R., Sette, G., Bakermans-Kranenburg, M. J., \& van IJzendoorn, M.H. (2013). Attachment the Italian way. Eur. Psychol. 18, 47-58. doi:10.1027/1016-9040/a000128

Cavanna, D. (2011). L'attaccamento e la dimensione interpersonale [Attachment and interpersonal dimension]. Giornale Italiano di Psicologia, 38(4), 783-788. ISSN: 03905349

Cavanna, D., Delogu, A.M., Zavattini, G.C. (2012). Le prospettive dell'attaccamento nei disturbi del comportamento alimentare [The perspective of attachment theory in eating disorders]. Psicologia clinica dello sviluppo, 16(1), 3 35. doi: 10.1449/37088.

Cole-Detke, H.E., Kobak, R. (1996), Attachment processes in eating disorder and depression, Journal of Consulting and Clinical Psychology, 64, pp. 282-290.

doi: org/10.1037/0022-006X.64.2.282

Cromer, J.A., Schembri, A.J., Harel, B.T., \& Maruff, P. (2015). The nature and rate of cognitive maturation from late childhood to adulthood. Frontiers in Psychology, 6 . doi: org/10.3389/fpsyg.2015.00704
Crowell, J.A., Waters, E., Treboux, D., O' Connor, E., Colon-Downs, C., Feider, O., et al. (1996). Discriminant validity of adult attachment interview. Child Development, 67(5), 2584-2599.

doi: $10.1111 /$ j.1467-8624.1996.tb01876.x

Dazzi, N., \& Zavattini, G.C. (2011). Il paradigma dell'attaccamento e la pratica clinica [Attachment paradigm and the clinical practice]. Giornale Italiano di Psicologia, 4, 729-756. doi: 10.1421/36100.

Delogu, A.M., Tortolani, D., \& Zavattini, G.C. (2008). La valutazione dell'attaccamento in famiglie anoressiche [The assessment of attachment in anorexic families]. Infanzia Adolescenza, 7, 98-109. doi: 10.3389/fpsyg.2015.01145.

Del Vecchio, E., Di Riso, D. Salcuni. S., Lis, A., \& George C. (2014). Anorexia and attachment: dysregulated defense and pathological mourning, Frontiers in Psychology/Psychology for Clinical Settings, 5, 1218, 2. doi: http://dx.doi.org/10.3389/fpsyg.2014.01218

Dias, P., Soares, I., Klein, J., Cunha, J. P. S., \& Roisman, G. I. (2011). Autonomic correlates of attachment insecurity in a sample of women with eating disorders. Attachment and Human Development , 13(2), 155-167. doi: $10.1080 / 14616734.2011 .554005$.

Fonagy P., Leigh T., Steele M., Steele H., Kennedy R., \& Mattoon, G. (1996). The relation of attachment status, psychiatric classification and response to the psychotherapy, Journal of Consulting and Clinical Psychology, 64, 2231. doi:org/10.1037/0022-006X.64.1.22.

Fonagy, P., Steele, M., Steele, H., \& Target, M. (1998). Reflective-Functioning Manual. Version 5.0. For application to Adult Attachment Interviews. Unpublished manual, University College, London.

Fonagy, P. \& Target, M. (1998). Mentalization and the changing aims of child psychoanalysis. Psychoanalytic Dialogues: The International Journal of Relational Perspectives, $8(1), 87-114$ doi:10.1080/10481889809539235

Fonagy, P. \& Target, M. (2001). Attaccamento e funzione riflessiva [Attachment and Reflective Functioning]. Milano: Raffaello Cortina Editore.

Garner, D. M. (2008). EDI-3 Eating Disorder Inventory. Giunti OS:Firenze.

Guarino, S. \& Vismara, L. (2012). Stato della mente rispetto all'attaccamento e funzione riflessiva in un gruppo di adolescenti autori di reato [Attachment states of mind and reflective functon in a group of adolescent offenders]. Psicologia clinica dello sviluppo, 3, 579-598. doi: 10.1449/38840

Ha, C., Sharp, C., Ensink, K., Fonagy, P. \& Cirino P. (2013). The measurement of reflective function in adolescents with and without borderline traits. Journal of adolescence, 36(6), 1215-23. doi: 10.1016/j.adolescence.2013.09.008

Jacobvitz, D.B., Hazen, N.L., \& Riggs, S.A. (1997). Disorganized mental processes in mothers, frightening/frightened caregiving and disoriented, disorganized behavior in infan$c y$. Paper presented at the biennial meeting of the Society for Research in Child Development, Washington, D.C.

Jeammet, P. (2006). Anorexie, boulimie. Maladies du paradoxe. Essai.

Laghi, F., Baiocco, R., Ghezzi, E., Petrocchi, N., \& Pace, C.S. (2012). La fiducia nell'attaccamento ai genitori e ai pari e i disturbi del comportamento alimentare in adolescenza. Psicologia Clinica dello Sviluppo, XVI(3), 557-578. doi: 10.1449/38839.

Main M., Goldwyn R., \& Hesse E. (2002). Adult Attachment Scoring and Classification System. Manoscritto non pubblicato. Department of Psychology, University of California, Berkeley. 
Möller, C., Falkenström, F., Holmqvist Larsson, M., \& Holmqvist, R. (2014). Mentalizing in Ypung offenders. Psychoanalytic psychology, 31(1), 84- 99.

doi: http://dx.doi.org/10.1037/a0035555

Obegi J. H. \& Berant, E. (2009). Attachment theory and research in clinical work with adults. New York: Guilford Press.

O'Shaughnessy R., \& Dallos, R. (2009). Attachment research and eating disorders: A review of the literature. Clinical Child Psychology and Psychiatry, 14(4), 559-574. doi: 10.1177/1359104509339082

Pace, C.S., San Martini, P., Zavattini, G.C. (2011). The factor structure of the Inventory of Parent and Peer Attachment (IPPA): a survey of Italian adolescents, Personality and Individual Differences, 51, 83-88. doi: 10.1016/j.paid.2011.03.006

Pace, C.S., Cavanna, D., Guiducci, V., Bizzi, F. (2015). When parenting fails: alexithymia and attachment states of mind in mothers of female patients with eating disorders. Frontiers in Psychology, 6, Article 1145, 1-11. doi: 10.3389/fpsyg.2015.01145

Preti, A., de Girolamo, G., Vilagut, G., Alonso, J., de Graaf, R., Bruffaerts, R., Demyttenaere, K., Pinto-Meza, A., Haro, J.M., Morosini, P., The ESEMeD-WMH Investigators (2009). The epidemiology of eating disorders in six European countries: Results of the ESEMeD-WMH project. Journal of Psychiatric Research, 43, 1125-1132. doi: 10.1016/j.jpsychires.2009.04.003

Ringer, F., \& Crittenden, P. (2007). Eating disorders and attachment: The effects of hidden family processes on eating disorders. European Eating Disorders Review, 15(2), 119-130. doi: 10.1002/erv.761

Rothschild-Yakar, L., Levy-Shiff, R., Fridman-Balaban, R., Gur, E., \& Stein, D. (2010). Mentalization and Relationships With Parents as Predictors of Eating Disordered Behavior, Journal of Nervous and Mental Disease, 7(198), 501-507. doi: 10.1097/NMD.0b013e3181e526c8

Russell, T.A., Schmidt, U., Doherty, L., Young, V., \& Tchanturia, K. (2009). Aspects of social cognition in anorexia nervosa: Affective and cognitive theory of mind. Psychiatry Research, 168 (3), 181-185. doi:10.1016/j.psychres.2008.10.028

Skårderud, F. (2007). Shame and pride in anorexia nervosa: a qualitative descriptive study. European Eating Disorders Review 15 (2), 81-97. doi: 10.1002/erv.774

Slade, A. (2010). Relazione genitoriale e Funzione Riflessiva. Teoria, clinica e intervento sociale [Parental relationship and Reflective Function. Theory, clinical and social intervention]. Roma: Astrolabio MMX.
Sprondel, V. Kipp, K. H., Mecklinger, A. (2011). Developmental Changes in Item and Source Memory: Evidence From an ERP Recognition Memory Study With Children, Adolescents, and Adults, Child Development, 6(82), 19381953. doi: 10.1111/j.1467-7687.2011.01130.x

Steele,' M. \& Baradon, T. (2004). Clinical use of the adult attachment interview in parent-infant psychotherapy, Infant Mental Health Journal 25(4), 284-299. doi: $10.1002 /$ imhj.20006

Steele, H. \& Steele M. (eds.) (2008a). Clinical applications of the Adult Attachment Interview. New York: Guilford Press.

Steele, H. \& Steele M. (2008b). Ten Clinical use of the Adult Attachment Interview. In H. Steele e M. Steele (Eds.) Clinical applications of the Adult Attachment Interview. (pp. 31-68). New York: Guilford Press.

Treasure, J Schmidt, U., \& van Furth E. (2006) The Handbook of eating disorders. Chichester: John Wiley and Sons.

Van IJzendoorn, M.H., Schuengel, C., \& BakermansKranenburg, M.J. (1999) Disorganized attachment in early childhood: Meta-analysis of precursors, concomitants, and sequelae Development and Psychopathology, 19(2), 225-250. doi: http://dx.doi.org/10.1037/gpr0000042

Wallin, D.J. (2009) Attachment in Psychotherapy. New York: Guilford Press.

Ward, A., Ramsay, R., Turnbull, S., Steele, M., Steele, H., \& Treasure, J. (2001). Attachment in anorexia nervosa: a transgenerational perspective, British Journal of Medical Psychology, 74, 497-505. doi: $10.1348 / 000711201161145$

Zachrisson, H., \& Kulbotten, G. (2006). Attachment in anorexia nervosa: An exploration of associations with eating disorder psychopathology and psychiatric symptoms. Eating and Weight Disorders, 11(4), 163-70. doi: 10.1007/BF03327567

Zachrisson, H. D. \& Skårderud, F. (2010). Feelings of insecurity: Review of attachment and eating disorders. European Eating Disorders Review, 18, 97-106. doi: 10.1002 /erv.999

Zavattini, G.C. (2002). La famiglia dell'adolescente: identità e trame familiari [The adolescent's family: identity and family scripts]. In (eds) M. Ammaniti: Manuale di psicopatologia dell'adolescenza [Manual of adolescence psychopathology] (pp.173-196.). Milano: Raffaello Cortina Editore.

Submitted: July 2015 Accepted: September 2015 Published: December 2015 